\title{
Article \\ Field Investigation and Rapid Deterioration Analysis of Heavy Haul Corrugation
}

\author{
Feng Jin ${ }^{1}\left(\mathbb{D}\right.$, Hong Xiao ${ }^{1, *}$, Mahantesh M Nadakatti ${ }^{2}{ }^{\oplus}$, Huiting Yue ${ }^{3}$ and Wanting Liu ${ }^{4}$ \\ 1 Beijing Key Laboratory of Track Engineering, Beijing Jiaotong University, Beijing 100044, China; \\ 18115066@bjtu.edu.cn \\ 2 Department of Mechanical Engineering, KLS Gogte Institute of Technology, Belagavi 590008, India; \\ mnadakatti@git.edu \\ 3 Zhengzhou Metro Group Co., Ltd., Zhengzhou 450000, China; 122331045@bjtu.edu.cn \\ 4 China Energy Investment Corporation Baoshen Railway Group Shenshuo Railway Co., Ltd. \\ Yulin 036203, China; 11252729@chnenergy.com.cn \\ * Correspondence: xiaoh@bjtu.edu.cn; Tel.: +86-10-5168-7247
}

check for updates

Citation: Jin, F.; Xiao, H.; Nadakatti, M.M.; Yue, H.; Liu, W. Field Investigation and Rapid Deterioration Analysis of Heavy Haul Corrugation. Appl. Sci. 2021, 11, 6317. https:// doi.org/10.3390/app11146317

Academic Editors: Giuseppe Lacidogna and Daniel Dias

Received: 27 May 2021

Accepted: 6 July 2021

Published: 8 July 2021

Publisher's Note: MDPI stays neutral with regard to jurisdictional claims in published maps and institutional affiliations.

Copyright: (c) 2021 by the authors. Licensee MDPI, Basel, Switzerland. This article is an open access article distributed under the terms and conditions of the Creative Commons Attribution (CC BY) license (https:// creativecommons.org/licenses/by/ $4.0 /)$.

\begin{abstract}
In this study, the rapid growth of corrugation caused by the bad quality of grinding works and their wavelength, depth, and evolution processes are captured through field measurements. The residual grinding marks left by poor grinding quality lead to further crack accumulation and corrugation deterioration by decreasing plastic resistance in rails. In this case, the average peak-topeak values of corrugation grow extremely fast, reaching $1.4 \mu \mathrm{m}$ per day. The finite element method (FEM) and fracture mechanics methodologies were used to analyze the development and trends in rail surface crack deterioration by considering rails with and without grinding marks. Crack propagation trends increase with residual grinding marks, and they are more severe in circular curve lines. To avoid the rapid deterioration of rail corrugation, intersections between grinding marks and fatigue cracks should be avoided.
\end{abstract}

Keywords: heavy haul railway; rail grinding; rail corrugation; sharp curve; fracture mechanics

\section{Introduction}

The Shenshuo heavy haul line, the transportation volume of which exceeds 260 million tons per year, is one of the most important freight lines in western China. It starts in Daliuta and ends in the west of Shuozhou. With increases in rail traffic volume and the axle loads, serious rail corrugation defects have appeared in some sections of the Shenshuo railway. Corrugation has resulted in an aggravation and worsening of defects in the track's structure, such as the fracture of fastenings, RCF defects, spalling, ballast crushing, etc. This has led to a sharp increase in maintenance costs and has affected the safety of heavy haul operations.

Rail corrugation, as an intractable defect in the railway industry, has a history of more than one hundred years [1]. It mainly occurs in heavy haul railways, high-speed railways (HSR), and urban rail transit, which includes all types of railway lines. For HSRs, the main wavelength of the corrugation in China is $120-150 \mathrm{~mm}$ [2]. It occurs both in the curves and along the straight lines of track sections, while wavelength is around $40-50 \mathrm{~mm}$ in metro lines [3]. Due to variations in the track and transport conditions [4], the wavelength of the corrugation is often longer than $150 \mathrm{~mm}$ in heavy haul lines. Furthermore, many researchers have introduced corrugation as a basic excitation in their numerical models to analyze W/R dynamic interactions [5], selection of track structures [6], or mitigation of rail defects [7]. Hence, it is important to diagnose the characteristics of corrugation and its evolution process. Grassie and Kalousek [8] summarized and classified the six typical rail corrugation modes according to the fixed wavelength mechanism and material damage mechanism. In 2012, they modified the understanding of the "wavelength fix" theory and 
introduced some devices that support continuous testing in the corrugation inspection field [9].

Within corrugation research, reproducing corrugation and revealing the mechanism of its formation are important topics.

As for research into damage mechanisms and the formation of corrugation defects, Meehan et al. [10,11] studied the influence of vehicle speed and its non-uniform distribution on wear-type corrugation growth rates. Jin and Wen $[4,12,13]$ analyzed the formation and development of corrugation at rail curves using Kalker's rolling contact theory with nonHertzian contact and friction work calculation for the worn-out material.

Other than analytical methods, field inspections play an important role in corrugation studies. Akira et al. [14] conducted a full-scale stand test to analyze corrugation formation mechanisms and concluded that the large creepage and vertical fluctuation of $\mathrm{W} / \mathrm{R}$ force is the main reason for the formation of corrugation. Torstensson [15] conducted a field experiment at a sharp curve line and analyzed the plastic material flow in the surface layer caused by the lateral creep forces. Teng et al. [16] constructed a measurement system with 2D laser sensors and a data splicing method to enlarge the effective wavelength of the measured corrugation data.

The topic of rail corrugation has attracted enough interest among researchers, and their research outcomes have been implemented in the mitigation of rail corrugation using a friction modifier $[17,18]$, a frequency regulation measurement $[19,20]$, and suggestions regarding the deficiency of current evaluation criteria have even been made [21]. Due to the complexity of the mechanism of rail corrugation, current understandings regarding corrugation are not sufficient to reach a consensus, and it still acts as a major and common defect in rail systems. Considering cost and installation difficulties, these mitigation measures are not always suitable for corrugation sites. Until now, the most effective and practical way to alleviate corrugation in a site was rail grinding. Practical experience shows that grinding works effectively extend the service life of a rail, and this method is verified not only in field experiences but also by metallographic observations [22]. The concept of preventive grinding [23], or a means by which to attain the optimal grinding strategy, has a practical significance [24]. It is important to understand the proper timing and strategy of rail grinding. However, an understanding of rail grinding quality, especially the effect of poor grinding quality on rail surface defects, also plays an important role in extending the service life of a railway.

To reveal the impact of poor grinding quality on the deterioration of rail corrugation, as well as the reason for this phenomenon's rapid development, this study carried out a 69-day-long field test on a sharp curve in a heavy haul railway. Based on the theory of fracture mechanics, FEM models, semi-Hertzian wheel-rail contact, and multi-body systems of heavy haul trains, reasons for the rapid development of rail corrugation are analyzed and mitigating suggestions are proposed.

\section{Field Tests}

Based on our field investigation, a continuously welded rail track (CWR) was used for the whole line and the rail was welded by online flash welding. For part of the worn rails that needed to be replaced, thermite welding was used. Most of this line runs freight trains with an axle load of $25 \mathrm{t}$ and an average velocity of $50 \mathrm{~km} / \mathrm{h}$. The superelevation was set as $105 \mathrm{~mm}$ on site, which was obviously too high for freight cars with low speed, such as the basic parameters shown in Table 1. 
Table 1. Basic parameters of the curve.

\begin{tabular}{cc}
\hline Types & Parameters \\
\hline Ambient temperature & $-25.5^{\circ} \mathrm{C}$ to $39.4^{\circ} \mathrm{C}$ \\
Rail temperature & $-25.5-59.4{ }^{\circ} \mathrm{C}$ \\
Radius & $400 \mathrm{~m}$ \\
Total length of curve & $414.54 \mathrm{~m}$ \\
Length of transition curve & $100 \mathrm{~m}$ \\
Cant & $1 / 40$ \\
Gradient & $7 \%$ o \\
Sleeper type & Type III \\
Superelevation & $105 \mathrm{~mm}$ \\
Average of vehicle speed & $50 \mathrm{~km} / \mathrm{h}$ \\
\hline
\end{tabular}

By the photos on sight, as shown in Figure 1a below, it can be seen that the rail in this section has a typical pattern of corrugation with a main wavelength of $160 \mathrm{~mm}$. The railhead is accompanied by obvious plastic flow patterns and spalling is common. In the trough of corrugation, the RCF (rolling contact fatigue) defects are significant. Figure $1 b, c$ shows the condition of the inner and outer rails of the curve. It can be seen from the pictures that the surface damage of the inner rail of the curve is severe, while the outer rail of the curve is in good condition.

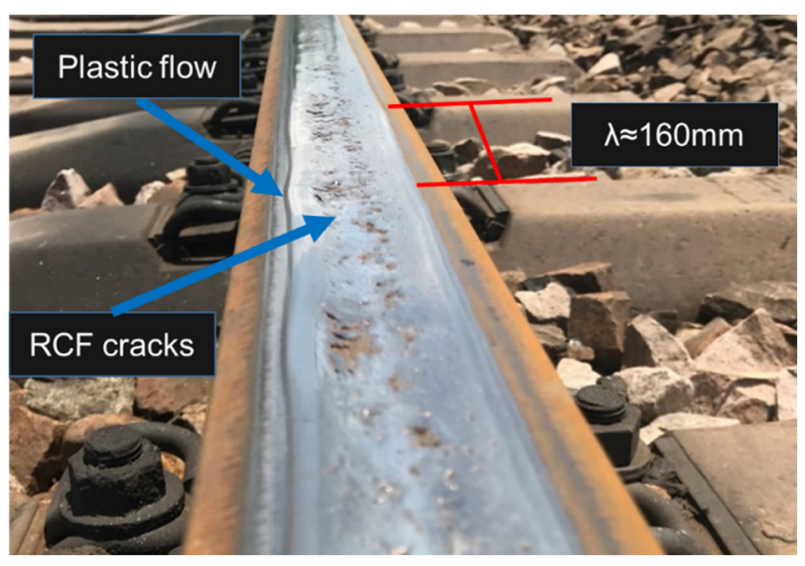

(a)

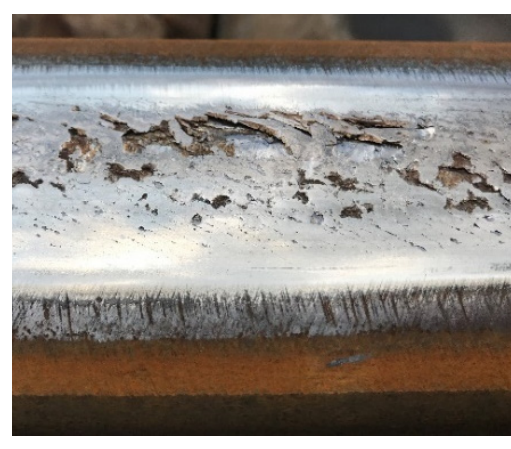

(b)

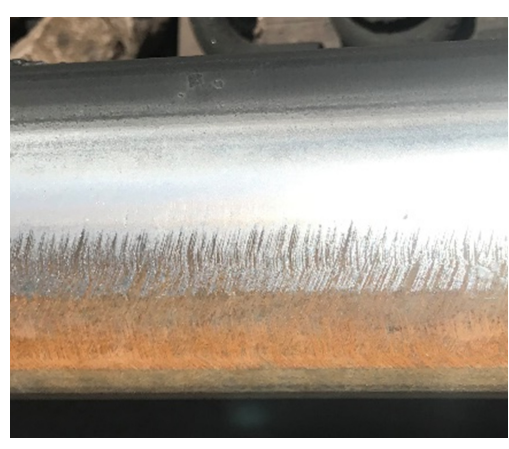

(c)

Figure 1. Typical corrugation cases and rail surface conditions: (a) typical rail corrugation in the field; (b) inner rail, the surface damage is serious; (c) the outer rail is in good condition. 


\subsection{Experimental Setup}

To obtain the corrugation properties along the heavy haul track, a corrugation analysis trolley (CAT) was used to test the roughness of the rail running band. The field measurement setup is shown in Figure 2.

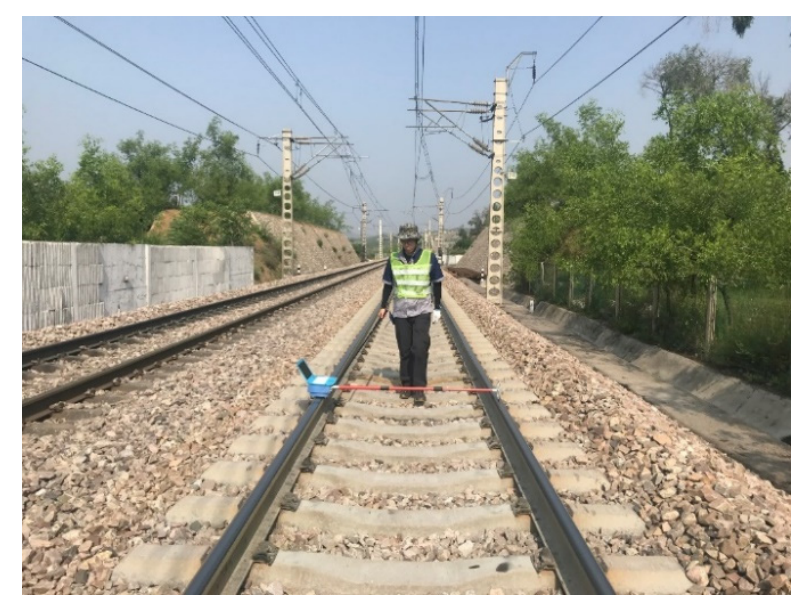

Figure 2. Field test by CAT.

\subsection{Field Testing Methodology}

\subsubsection{Testing Setup}

The initial repair work by grinding was carried out on 19 April 2018. It was the first day of field testing to study the rail corrugation mechanism. According to the fast development process of heavy haul corrugation, the measurement was carried out in intervals of 2-4 days (the time of maintenance was given as $2-3$ days a week). It should be noted that, on the 24th day of testing, a grinding car passed through the test track with poor grinding quality. The target profile of the grinding car was the standard $75 / \mathrm{kg}$ profile used in China, which is mainly used for heavy haul railways, and the dimensions of the grinding wheels are $250 \mathrm{~mm} \times 75 \mathrm{~mm}$ (Diameter $\times$ Thickness).

\subsubsection{Evaluation Indicators}

When rail surface roughness is measured by equipment in the field, some of the measured data have obvious fluctuations due to variations in the weather, temperature, and abnormal working conditions. Therefore, in the current study, EN 15610:2009 was used as the international standard of reference for preprocessing the data [25].

This test mainly measures peak-to-peak values, rail roughness level, cumulative percentage of magnitude, and other indicators to describe the severity and evolution of the corrugation on the test rail track on the following basis:

1. Peak-to-peak values and allowable over-limit

Based on the recommendations of corrugation measurements and the evaluation standards of EN 13231-3:2012 [26], the moving average peak-to-peak values of corrugation were used as the index of rail corrugation amplitude in this paper. The moving average of peak-to-peak values within a window length of $L$ can be calculated as:

$$
\operatorname{PPV}(X, L)=\left(a_{1}+a_{2}+a_{3}+\cdots+a_{n}\right) / n
$$

where $a_{n}(n=1,2,3, \cdots, n)$ is the individual peak-to-peak irregularities within the window of length $L$ as shown in Figure 3, and $\mathrm{x}$ is the calculation location of peak-to-peak values. 


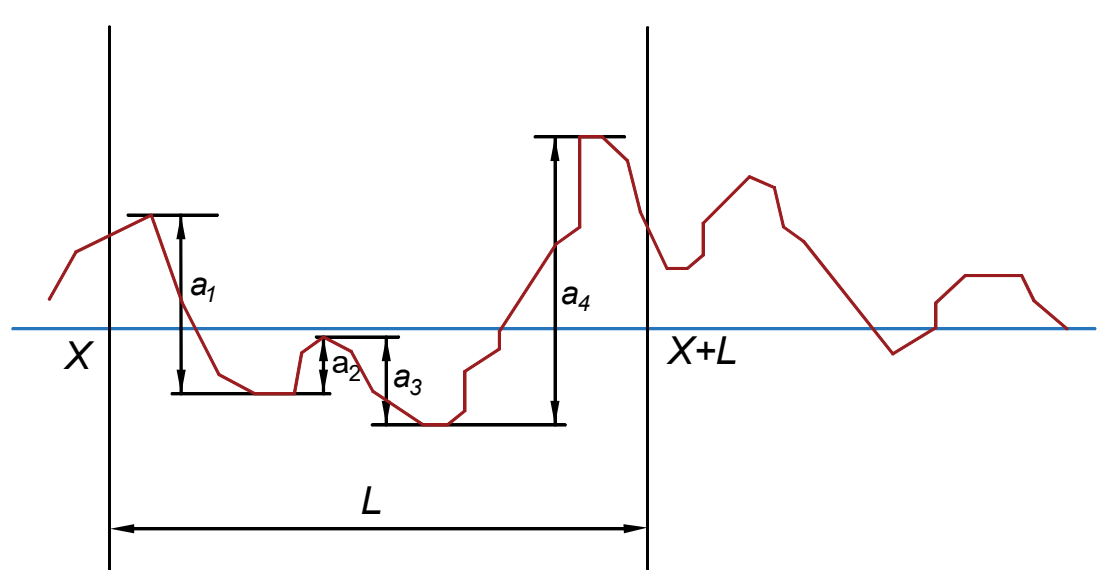

Figure 3. Calculation of peak-to-peak values of corrugation.

In EN 13231-3:2012, the wavelength range related to corrugation is divided into 4 groups: (1) $10-30 \mathrm{~mm}$, (2) $30-100 \mathrm{~mm}$, (3) $100-300 \mathrm{~mm}$, and (4) $300-1000 \mathrm{~mm}$. The analysis window length and allowable limits are specified in Table 2.

Table 2. The evaluation criteria of the European Railway Union.

\begin{tabular}{ccccc}
\hline Wavelength/mm & $\mathbf{1 0 - 3 0}$ & $\mathbf{3 0 - 1 0 0}$ & $\mathbf{1 0 0 - 3 0 0}$ & $\mathbf{3 0 0 - 1 0 0 0}$ \\
\hline Window $/ \mathrm{mm}$ & 150 & 500 & 1500 & 5000 \\
Peak-to-peak limit $/ \mu \mathrm{m}$ & 10 & 10 & 15 & 75 \\
Allowable percentage $/ \%$ & - & 10 & 10 & - \\
\hline
\end{tabular}

There are no separate amplitude requirements for corrugation in heavy haul transit railways in China. The standard of corrugation evaluation in separate wavelengths is only carried out for HSR. The requirement of the HSR [27] was also added as a standard of comparison.

2. Roughness level

The rail surface roughness test is mainly based on the analytical methods of EN ISO 3095:2013 [28] and GB/T 3449-2011 [29]. The one-third octave analysis method is used for processing, and the value defined in the specification is compared with the value measured in the field.

\section{3. $\mathrm{CDF}$ (Cumulative Distribution Function)}

The CDF values of rail corrugation are compared with the CLASS 2 level of the EN 13231-3: 2012 because the control requirements of heavy haul railways are lower than those of other railways.

\section{Observation of Rapid Deterioration of Rail Corrugation under Poor Grinding Quality}

\subsection{Development Charateriscs of the Rail Corrugation under Grinding Works}

Figure 4a,b shows the change in roughness level of the test section from April 2018 to June 2018. The number on the right of the measured data in the legend indicates the operational days from the test's commencement. It can be seen from Figure 4a that, during the first 22 days of the test (the transport volume was about 16 million tons), the levels of roughness on the rail's surface developed slowly and the curves were stable. After the first grinding, there was a significant peak in the $50 \mathrm{~mm}$ wavelength, and it disappeared in a short period of time that was no longer than 3 days. From Figure $4 b$, it is obvious that overall roughness showed a significant upward trend on the 24th day of the test, which was when the second grinding works were finished. Under the load of the heavy haul 
train, the main wavelength of the corrugation varied in the range of $125-160 \mathrm{~mm}$. On the 69th day of the test, the wavelength stabilized at $160 \mathrm{~mm}$.

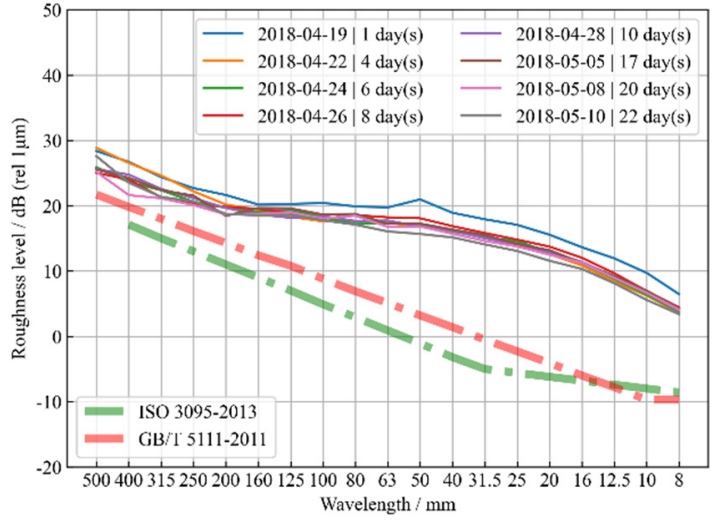

(a)

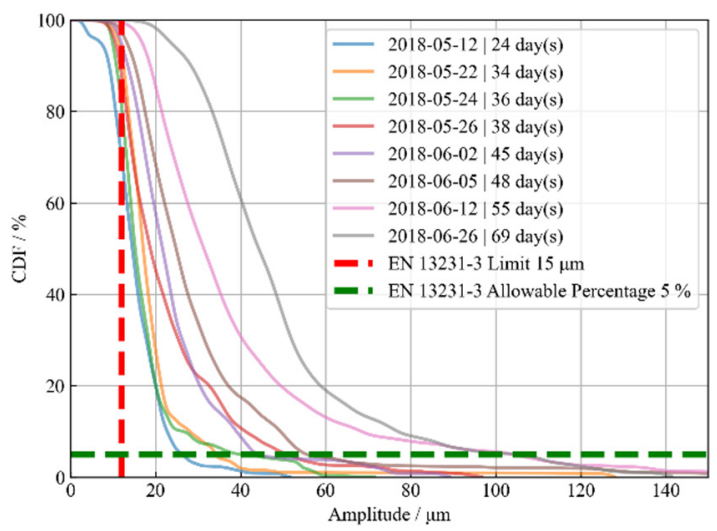

(c)

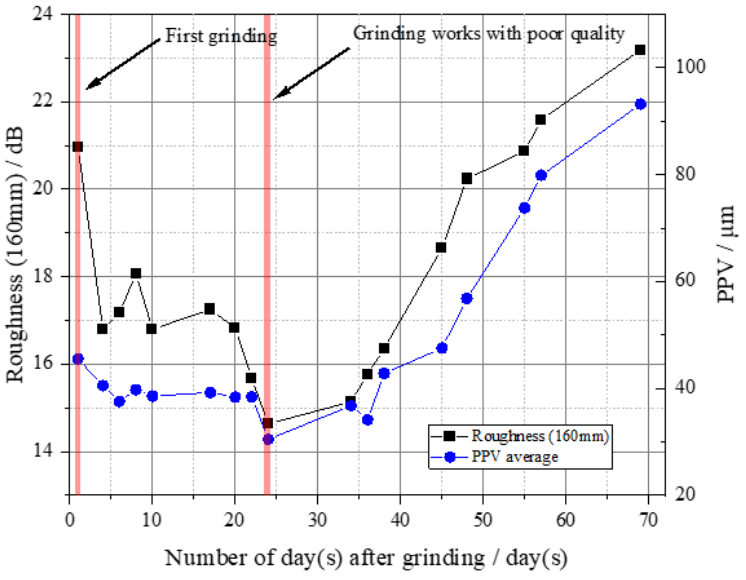

(e)

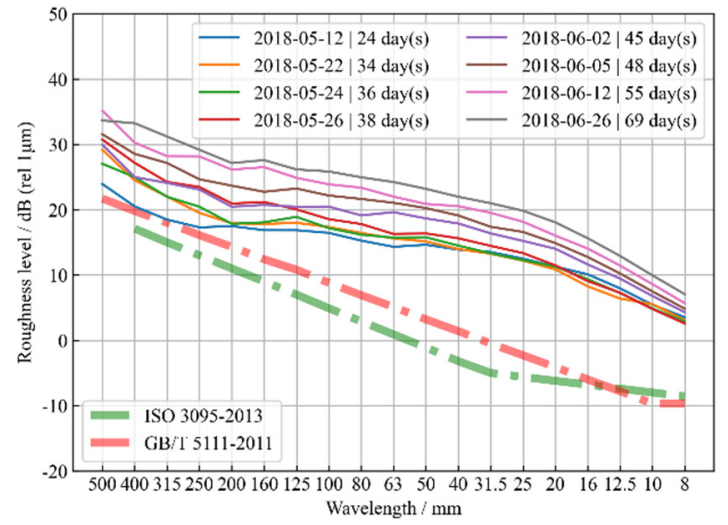

(b)

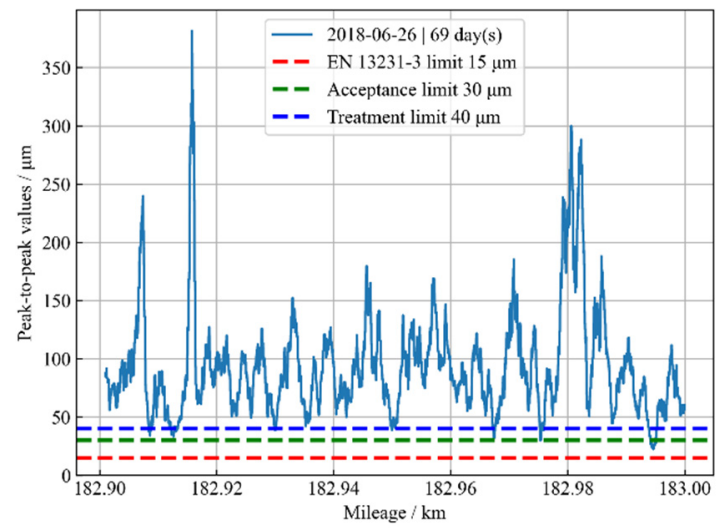

(d)

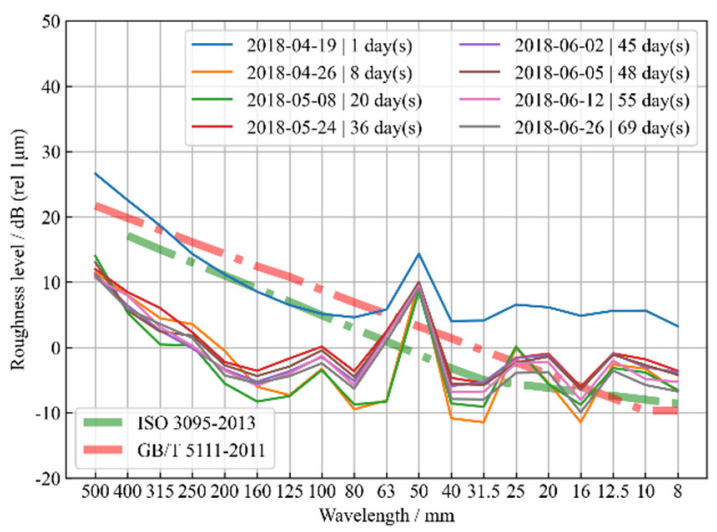

$(\mathbf{f})$

Figure 4. Variation trends in amplitude and frequency domain of corrugation from field test: (a) stable state; (b) rapid deterioration state; (c) CDF of peak-to-peak values during the rapid deterioration period; (d) peak-to-peak value of the last field test on inner rail; (e) the evolution process of corrugation with dates; (f) the trend in one-third octave (outer rail).

By comparing Figure $4 a$ with Figure $4 b$, it is apparent that the poor grinding works accelerated corrugation formation from a stable state, which means grinding quality and grinding timing played important roles in the process of corrugation development. From 
the CDF contrast plotted in Figure 4c, it can be seen that the trend in corrugation amplitude growth is stable, and far exceeds the recommended value of EN specification. Figure $4 \mathrm{~d}$ shows the peak-to-peak value of the last corrugation test in the field test arrangement. It can be seen from the figure that, 69 days after the first grinding, the maximum peak-to-peak value exceeded $350 \mu \mathrm{m}$. In the majority of the sections, the peak-to-peak corrugation values exceeded $100 \mu \mathrm{m}$; over the entire section, they exceeded the regulatory acceptable limit of $30 \mu \mathrm{m}$.

Figure 4e shows the variation trend of rail roughness at the $160 \mathrm{~mm}$ wavelength range and the peak-to-peak mean value of rail corrugation during the study time period. It can be seen from the figure that, after the initial rail grinding, rail roughness and average peakto-peak values are relatively stable, and there is no observable change in this trend during the initial 22 days of the test. After grinding works with poor quality, the rail roughness level at the wavelength of $160 \mathrm{~mm}$ and wave depth show an obvious rising trend. This represents a linear growth trend, with the average peak-to-peak value increasing at a rate of $1.4 \mu \mathrm{m}$ per day.

Figure $4 \mathrm{f}$ shows the evolution of the roughness of the outer rail. As can be seen from the graph, during the full test period, the deterioration trend was indistinct, and the state of the rail's surface was better than that of the inner rail. After the first grinding, there was a significant peak in the $50 \mathrm{~mm}$ wavelength; however, unlike in the inner rail, it was kept up until the end of the test.

\subsection{Reasons for the Rapid Development of Corrugation}

From the figures and data shown above, we can conclude that the grinding works will leave grinding marks because of the rolling of the grinding wheels. Roughness will be increased by the grinding marks, but it will also decrease in a short period of time because of the wear or plastic deformation between the heavy haul wheel and the rail. However, when it comes to the poor-quality grinding works, it seems there are no effects on the outer rail, while the roughness level of the inner rail increases sharply. Railhead photos taken after the two grinding processes are needed to attain reliable answers to the questions above.

Figure $5 \mathrm{a}$ is a picture of the rail surface after the initial grinding on site. It can be seen from the picture that, although the rail was ground and repaired, the central crack in the rail's surface could not be eliminated entirely. This is due to the unregular profile of the inner rail that is caused by severe corrugation defects.

Figure $5 \mathrm{~b}$ is a picture of the rail surface after the second grinding car passed by on the 24th day after grinding. Compared with the initial grinding, the rail's surface damage was not eliminated after the second grinding vehicle with poor grinding quality was used. Instead, there are more obvious grinding marks at the center of the rail's top where the fatigue cracks are concentrated, and they intersect with the original fatigue cracks.

Regarding the effect of grinding marks on the outer rail, the grinding marks become worn in a short period of time. This is because there are no defects on the outer rail, as shown in Figure 1c. Combining all of the points all, the rapid deterioration of corrugation observed in the field under poor grinding quality could be summarized as follows:

When the second grinding car passed by on the 24th day of the test, poor grinding quality led to the interference between the grinding marks and the surface cracks. This made the rail's surface cracks change from a stable state to an unstable state, leading to further development. Crack propagation leads to a decrease in the overall anti-plastic ability of a rail's surface [30], in this case, the ratcheting and hardening mechanisms come into play. Under the multi-axis loading state from additional higher heavy haul vehicle loads, a rail's surface condition deteriorates rapidly, the plastic flow on the rail's surface becomes aggravated, and corrugation develops rapidly. Induced corrugation will further increase the wheel and rail forces and accelerate the evolution of plastic flow corrugation to a point beyond the allowable safety operating standards. In the whole process, residual 
marks accelerated the evolution process of corrugation and made the corrugation reach a rapid developmental stage.
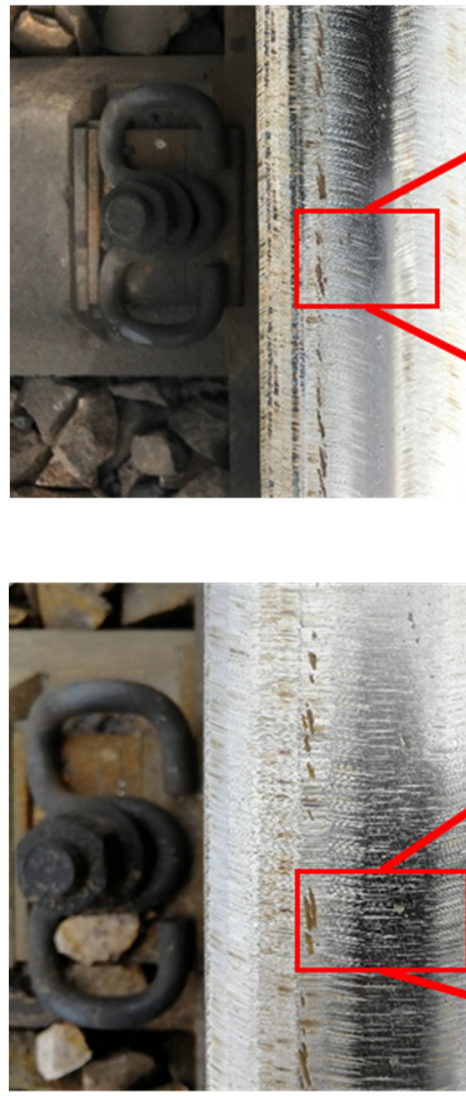

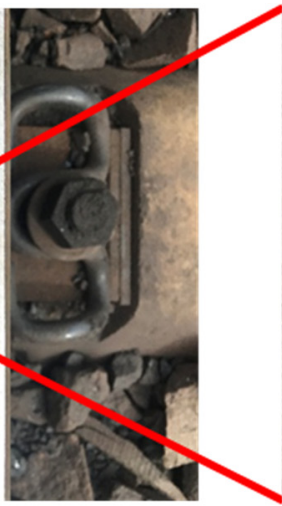

(a)

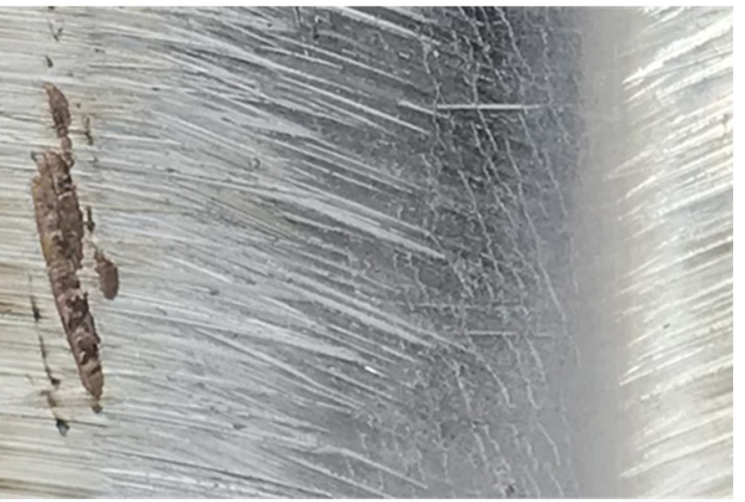

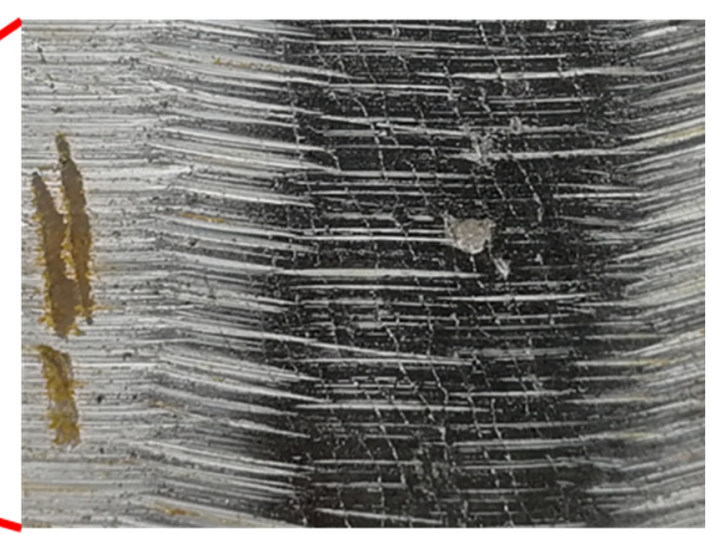

(b)

Figure 5. Railhead state after two times of grinding works: (a) cracks do not intersect with grinding marks after first grinding works; (b) cracks intersect with grinding marks after second grinding works with poor grinding quality.

\section{Multi-Crack Expansion Analysis Considering Grinding Marks}

In order to theoretically analyze the fracture characteristics in the process of the intersection of residual grinding marks and cracks, a fracture analysis of the micro-cracks on the rail's surface, both with and without grinding marks, was carried out by the FEM technique. A wheel load was applied to the finite element model of crack analysis by the Python and ABAQUS subroutines. The entire crack analysis is shown in Figure 6 and the detail parameters of the numerical model are provided in Table 3.

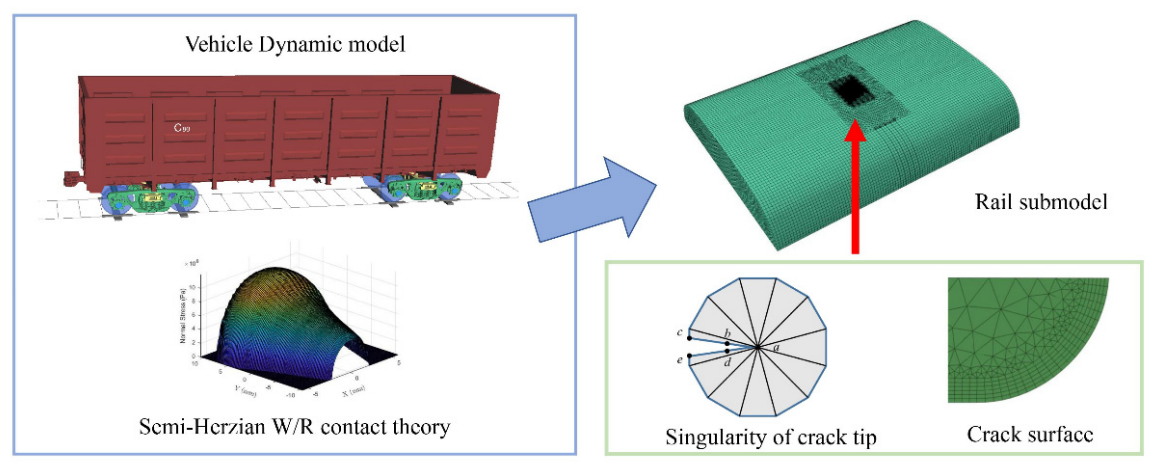

Figure 6. General description of construction process of crack analysis model. 
Table 3. Basic parameters of the model.

\begin{tabular}{cc}
\hline Types & Parameters \\
\hline Vehicle type & $\mathrm{C} 80$ \\
Axle load & $25 \mathrm{t}$ \\
Distance between bogie centers & $8300 \mathrm{~mm}$ \\
Wheelbase & $1830 \mathrm{~mm}$ \\
Rail type & $75 \mathrm{~kg} / \mathrm{m}$ \\
Elastic modulus of rail & $205.9 \mathrm{GPa}$ \\
Wheel tread type & $\mathrm{LM}$ \\
\hline
\end{tabular}

\subsection{Stress Intensity Factor Calculation Based on Displacement of Singular Element}

Regarding the problem of rapid corrugation deterioration discussed in previous sections, there are some basic issues that should be considered such as RCF cracks, crosses between the grinding marks, and the influence of the cracks on the corrugation et al. By considering the applicability of the methodology and the accuracy of the solution, a stress intensity factor (SIF) based on the displacement of the singular element is selected to analyze surface crack characteristics of a rail under grinding mark conditions.

The calculation of stress intensity factor based on the displacement method can be carried out by Formula (1):

$$
\left\{\begin{aligned}
K_{\mathrm{I}} & =\frac{\mu \sqrt{2 \pi}}{\sqrt{r}(2-2 v)}\left(v_{\mathrm{c}}-v_{\mathrm{a}}\right) \\
K_{\mathrm{II}} & =\frac{\mu \sqrt{2 \pi}}{\sqrt{r}(2-2 v)}\left(u_{\mathrm{c}}-u_{\mathrm{a}}\right) \\
K_{\mathrm{III}} & =\frac{\mu \sqrt{\pi}}{\sqrt{2 r}}\left(w_{\mathrm{c}}-w_{\mathrm{a}}\right)
\end{aligned}\right.
$$

where $\mu$ is the Shear Modulus; $v$ is Poisson's ratio; $r$ represents the distance between the analytically calculated node and the crack tip; Based on the $1 / 4$ three-dimensional singular element in FEM, the Formula (1) can be optimized as:

$$
\left\{\begin{aligned}
K_{\mathrm{I}} & =\frac{\mu \sqrt{2 \pi}}{\sqrt{r}(2-2 v)}\left[4\left(v_{\mathrm{b}}-v_{\mathrm{d}}\right)+v_{\mathrm{e}}-v_{\mathrm{c}}\right] \\
K_{\mathrm{II}} & =\frac{\mu \sqrt{2 \pi}}{\sqrt{r}(2-2 v)}\left[4\left(u_{\mathrm{b}}-u_{\mathrm{d}}\right)+u_{\mathrm{e}}-u_{\mathrm{c}}\right] \\
K_{\mathrm{III}} & =\frac{\mu \sqrt{\pi}}{\sqrt{2 r}}\left(w_{\mathrm{c}}-w_{\mathrm{a}}\right)
\end{aligned}\right.
$$

where $v_{i}, u_{i}, w_{i}(i=\mathrm{a}-\mathrm{e})$ are the vertical, lateral and longitudinal displacements at the calculation point $i$; and a-e represent the numerical integration points in FEM, as shown in Figure 6.

\subsection{Establishment of a Multi-Crack Model}

For the process of crack simulation based on the classical theory of fracture mechanics, knowing how to divide crack elements and how to solve the singularity of the crack's tip are key challenges. In order to solve the singularity of the crack tip, a 1/4 singular element was used to describe the tip of the cracks. The elements with the types C3D15 and C3D20 supported by commercial finite element software ABAQUS are used to mesh the template part of the crack. The total element number is around 1.5 million and the minimum distance at the crack tip is $0.01 \mathrm{~mm}$.

As shown in Figure 7, the depth of the crack is set to $0.1 \mathrm{~mm}$ when the crack length is set as $10 \mathrm{~mm}$ from the field investigation. The crack angle was $20^{\circ}$ from the longitudinal direction of the rail, and five parallel cracks were considered for the railhead finite element model. For the model with the grinding marks, the width and depth of the grinding marks were set to $0.2 \mathrm{~mm}$, according to the measurement results by the portable optical microscope in the field shown in Figure 8. The grinding marks were set to $15 \mathrm{~mm}$ and perpendicular to the train's movement direction, respectively, according to the on-site studies through photographs and the setting location of the grinding wheel. 


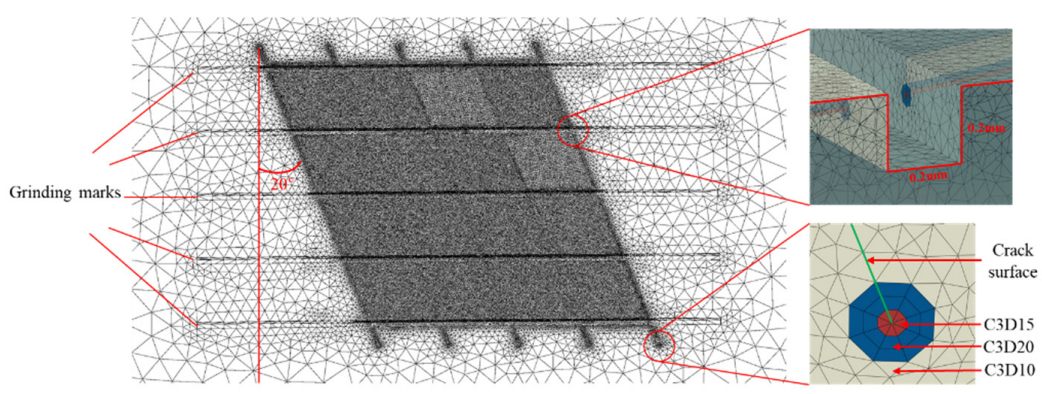

Figure 7. Schematic diagram of crack model with grinding marks.

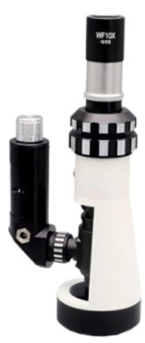

(a)

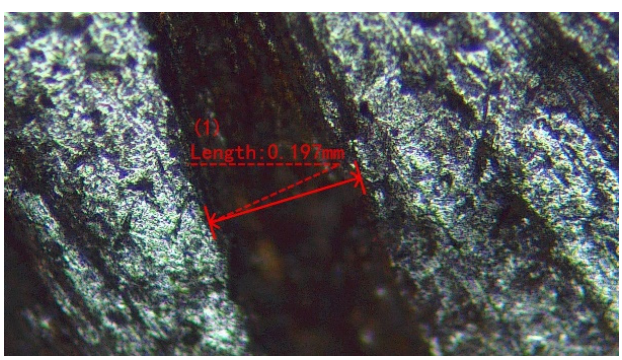

(b)

Figure 8. Measurement of the grinding marks by portable optical microscope: (a) portable optical microscope; (b) the picture of the grinding marks and the results after calibration.

For the load applied to the wheel and rail parts, the models of heavy haul railway C80 vehicles with an axle load of $25 \mathrm{t}$, based on multi-body dynamics, were established, and their basic parameters are shown in Table 1.

The semi-Hertzian wheel-rail contact algorithm [31,32] was used to calculate the wheel-rail contact state. The lateral creep force, longitudinal creep force, and contact surface normal force were applied to the railhead sub-model. Among these, the normal contact forces and their adhesion states to the straight line, transition curve, and circular curve sections were calculated using the rail profile measured by MiniProf, as shown in Figure 9. From the figure, we can see that the railhead of the inner rail is flatter than it is in the outer rail, and both of the profiles show a significant difference from the standard profile after grinding. The main reason for this is that the deformation of the railhead is severe, which provides an extra challenge to the grinding works when attempting to obtain the ideal profiles of rails after grinding.

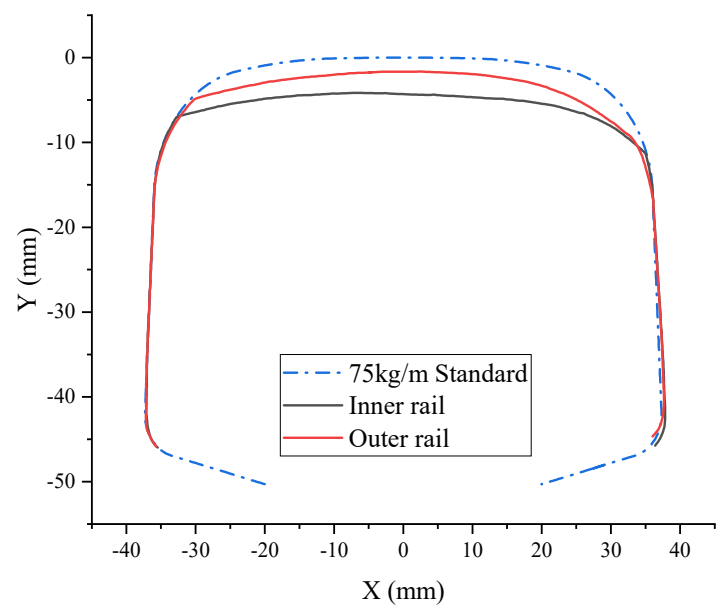

Figure 9. Measured profile after grinding by MiniProf. 
According to Figure 10, it is clear that, due to the difference between the actual rail grinding profile and the standard $75 \mathrm{~kg} / \mathrm{m}$ profile, $\mathrm{W} / \mathrm{R}$ contact occurred at the center of the railhead, which is different to the general $\mathrm{W} / \mathrm{R}$ contact calculation between the new profile of the wheel and the rail.

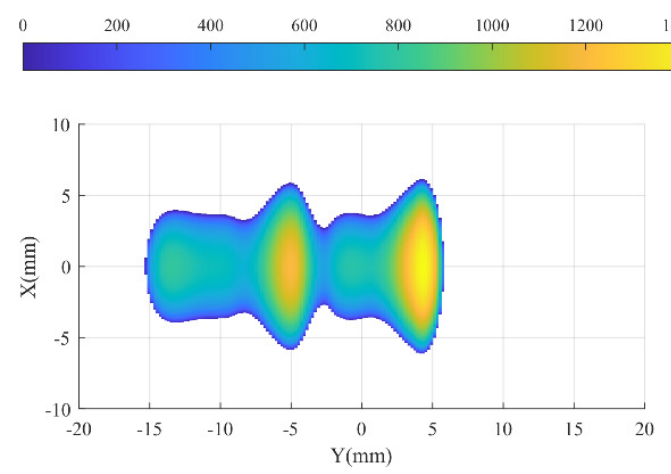

(a)

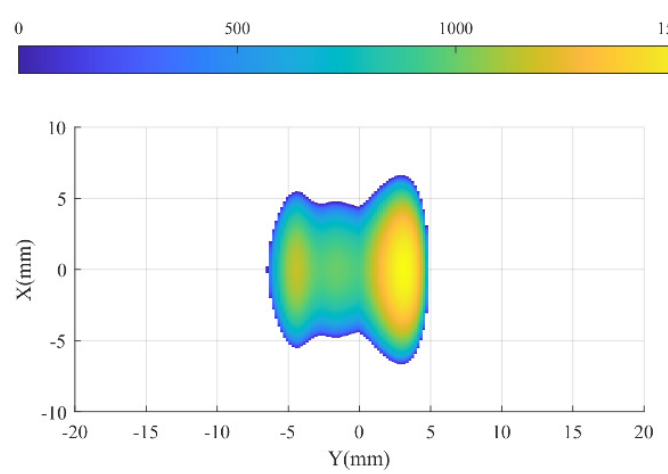

(c)

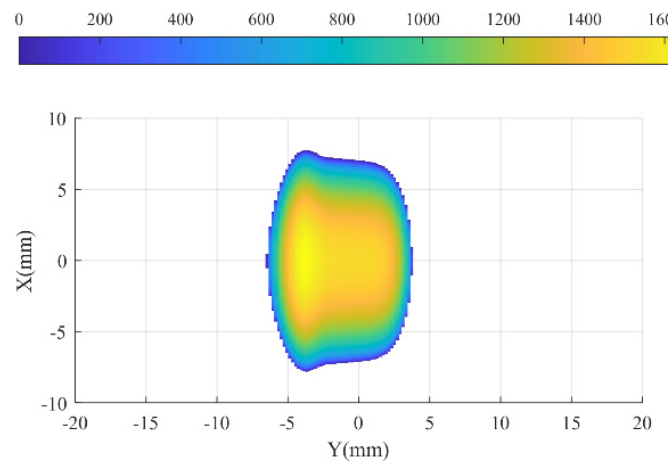

(e)

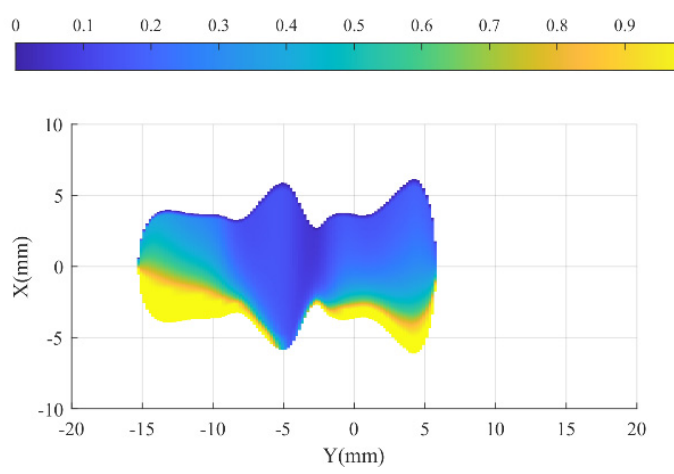

(b)
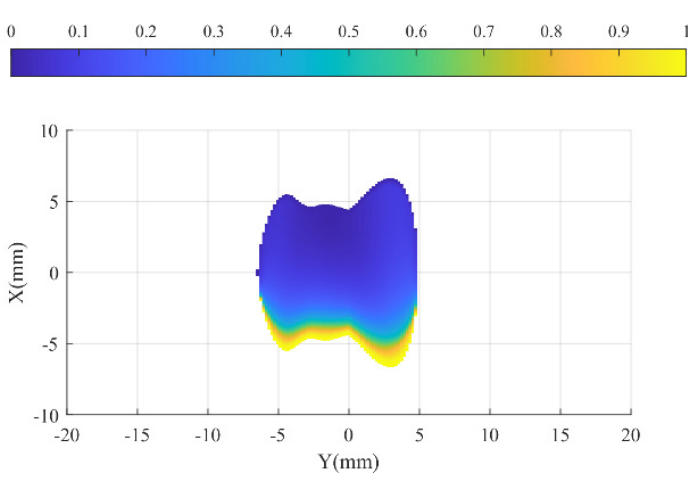

(d)
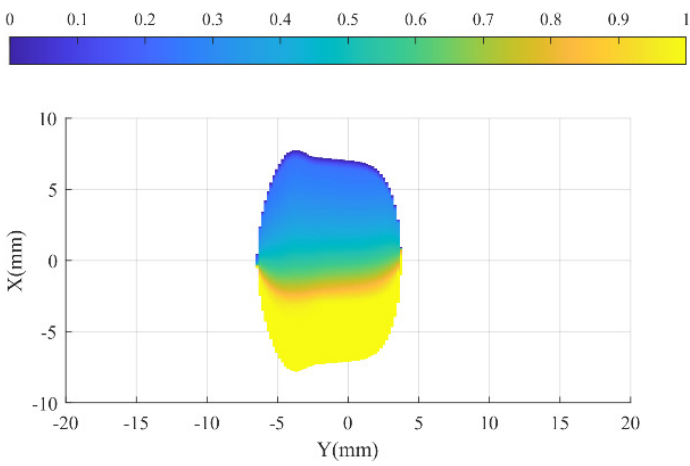

$(\mathbf{f})$

Figure 10. $W / R$ contact stress distribution with the semi-Hertzian method considering non-elliptical contact patch: (a) normal contact stress in a straight line; (b) traction coefficient in a straight line; (c) normal contact stress in a transition curve; (d) traction coefficient in a transition cure; (e) normal contact stress in a curve section; (f) traction coefficient in a circular curve.

\subsection{Result Analysis}

Based on the theory of fracture mechanics, the crack tip propagation characteristics of the rail's surface were analyzed by the evaluation of SIF. The sign $(+/-)$ of stress intensity represents the crack's opening or sliding direction, and the amplitude represents magnitude. For the tensile (type I) cracks, only tensile stress is considered for crack development. For 
the sliding type (type II) and the shearing (type III) of crack propagation, both negative values and positive values in the SIF will cause the crack to expand.

In order to attain a better answer about the fact that corrugation in the field is more likely to occur in a curved section than in a straight line or in a transition, the section sets related to straight lines, transition curves, and curved sections are analyzed simultaneously for comparative purposes.

\subsubsection{Straight Line}

Figure 11a,b show the results of the SIFs of type I cracks in a straight line. It can be observed from the figures that the values of both models are not significant because of the small tangential stress; however, around the boundary of the contact patch, the values of the SIFs are higher than the crack tips within the contact patch. Figure 11c,d show the crack propagation state of type II cracks in a straight line. For the cases without grinding marks, the $K_{\mathrm{II}}$ value is mainly distributed in the contact area, and higher SIF values appear in the sliding area. When comparing the models without the grinding marks to one another, the maximum value of $K_{\mathrm{II}}$ is higher than the case without the grinding marks. Apart from this, the values of type II SIF are higher than at the area where grinding marks and cracks intersect in the contact area. As for the results of the values of type III SIF shown in Figure 11e,f, the grinding marks also enlarge the SIF values.

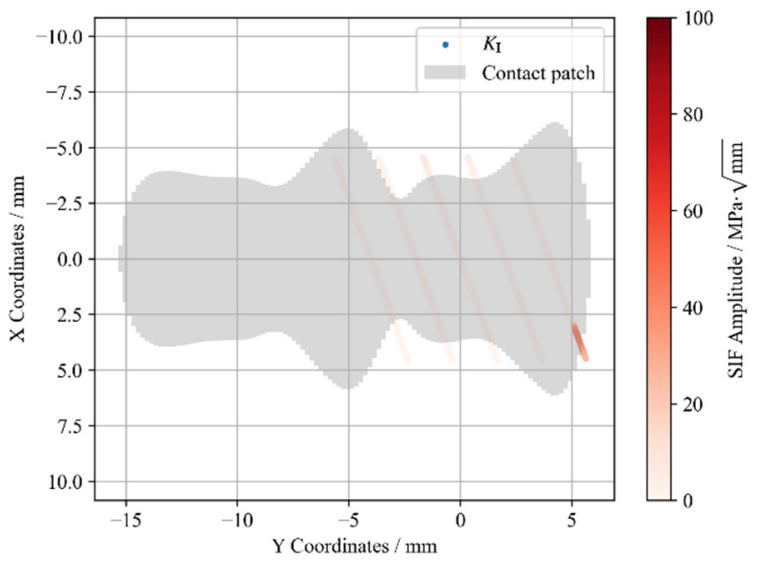

(a)

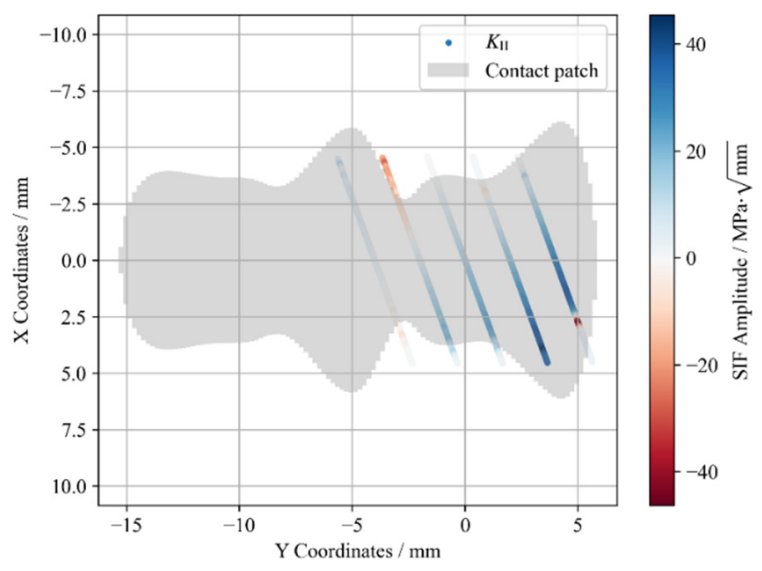

(c)

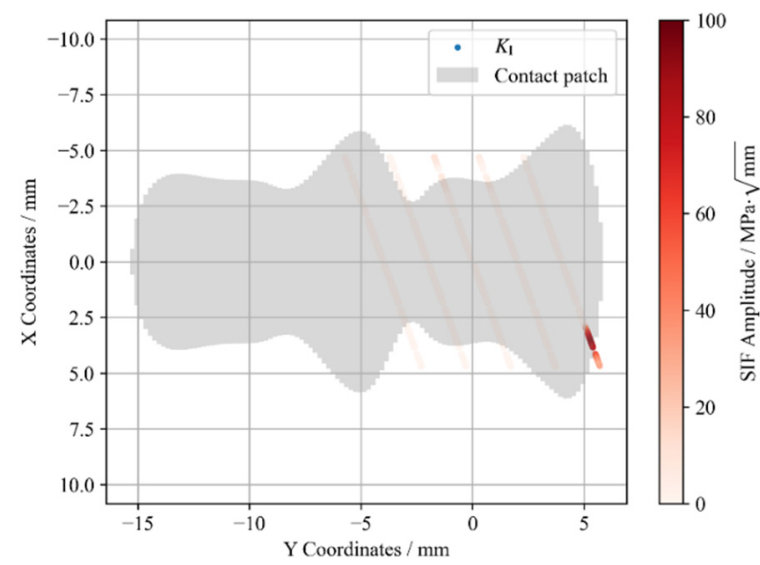

(b)

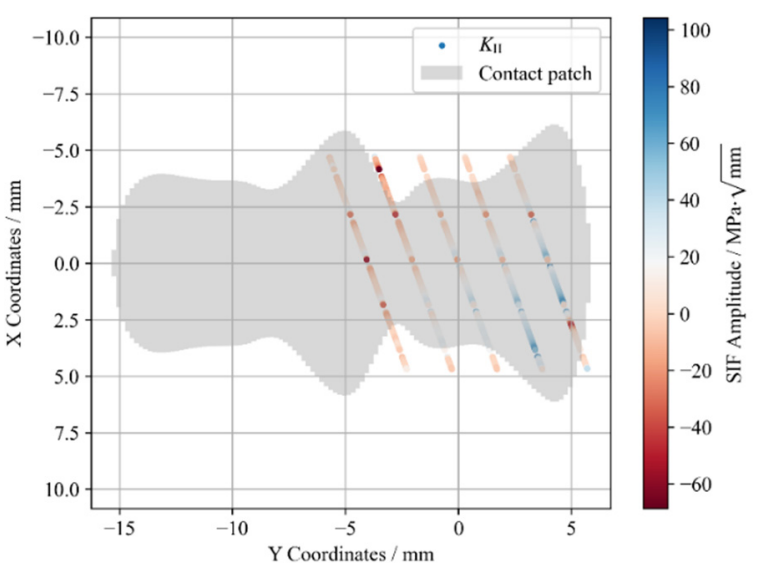

(d)

Figure 11. Cont. 


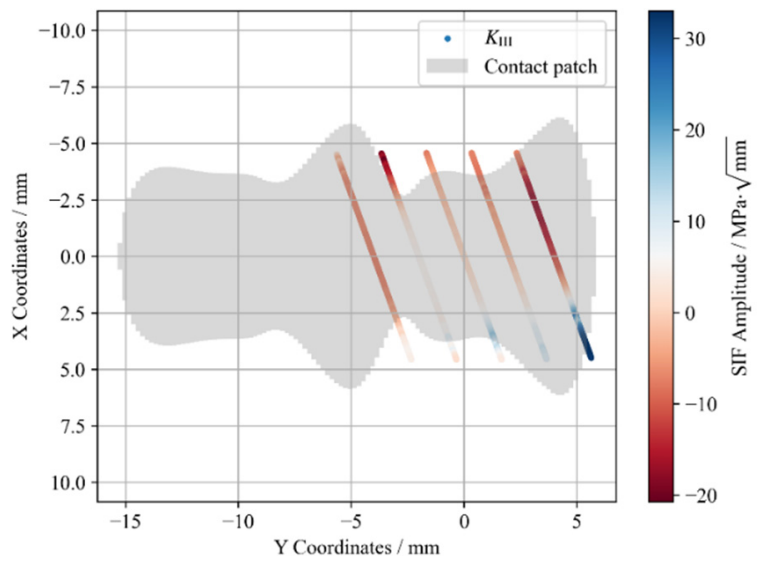

(e)

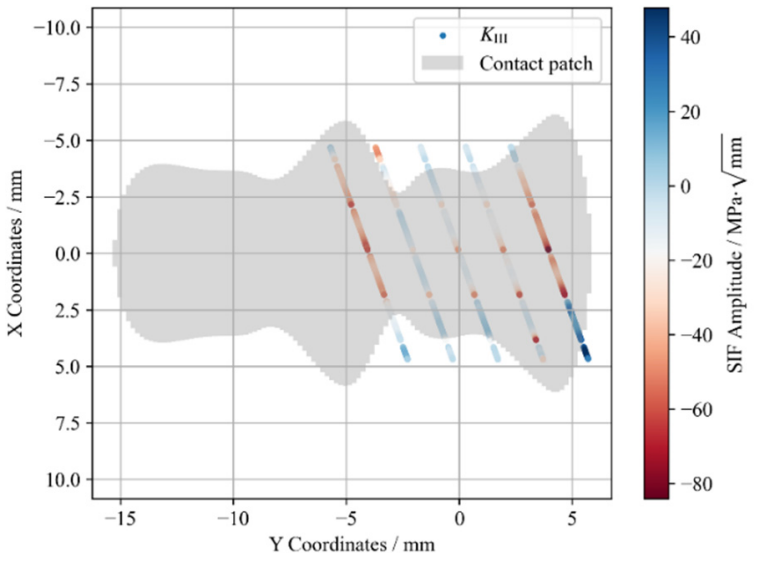

(f)

Figure 11. Results of SIFs at the straight line: (a) SIF of type I cracks without the grinding marks; (b) SIF of type I cracks with the grinding marks; (c) SIF of type II cracks without the grinding marks; (d) SIF of type II cracks with the grinding marks; (e) SIF of type III cracks without the grinding marks; (f) SIF of type III cracks with the grinding marks.

\subsubsection{Transition Curve}

Figure 12a,b are the result of an SIF of type I crack in the transition section. As can be seen from the figure, the trend in tensile type crack propagation is similar between both cases with and without grinding marks. The values of SIF appear to be high in the areas near the contact patch, and their absolute value is higher than it is along the straight line. In the transition curve section, the distribution of SIF of type II cracks with and without grinding marks is similar to the straight section. A higher value of SIF is generated in the area where grinding marks and cracks intersect, as shown in Figure 12c,d. As for the results of the SIF values of type III cracks shown in Figure 12e,f, the grinding marks also enlarge the values of SIF in the area where grinding marks and cracks intersect.

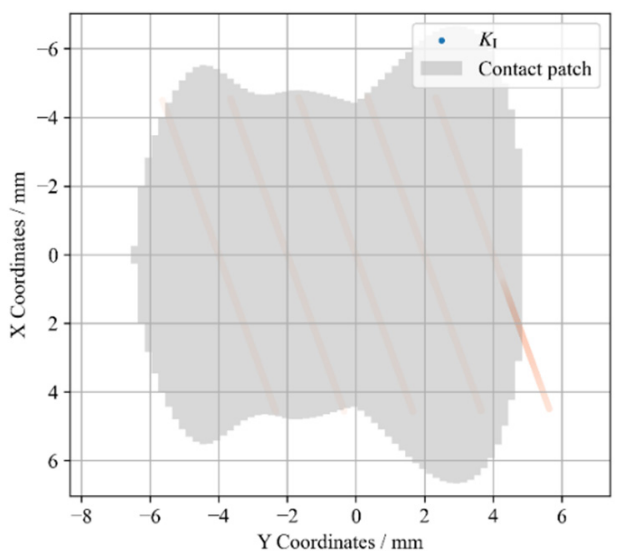

(a)

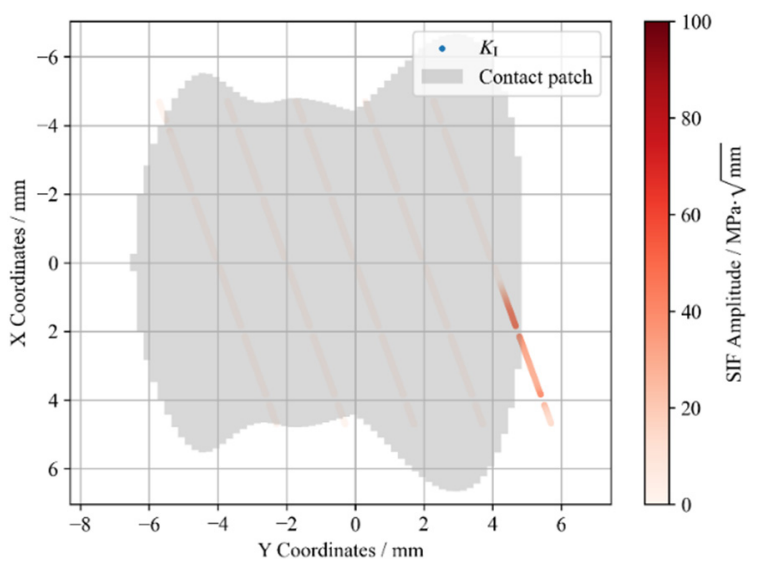

(b)

Figure 12. Cont. 


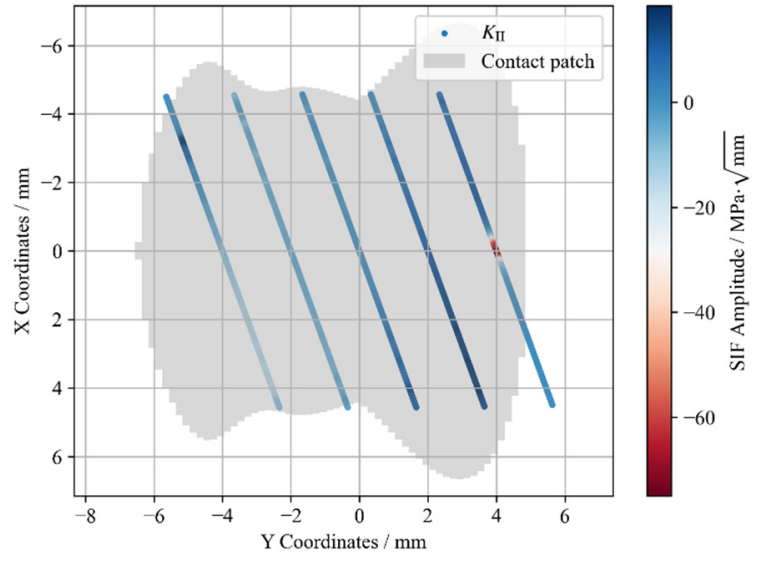

(c)

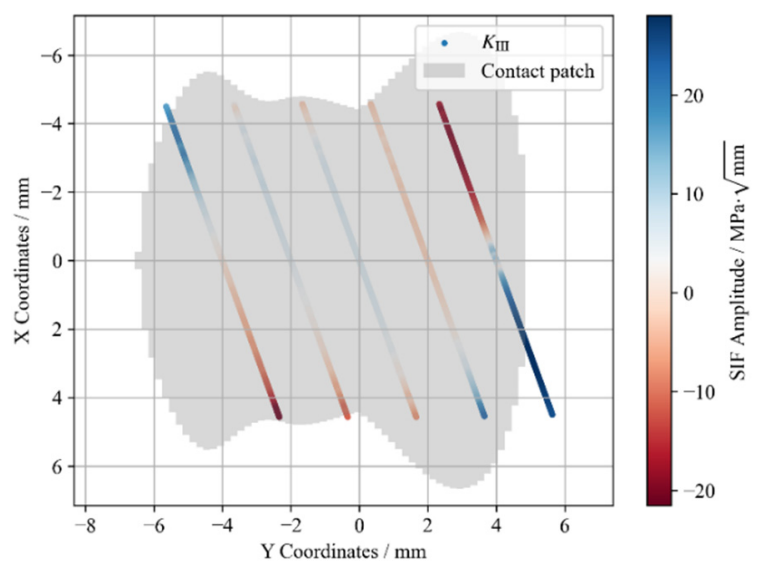

(e)

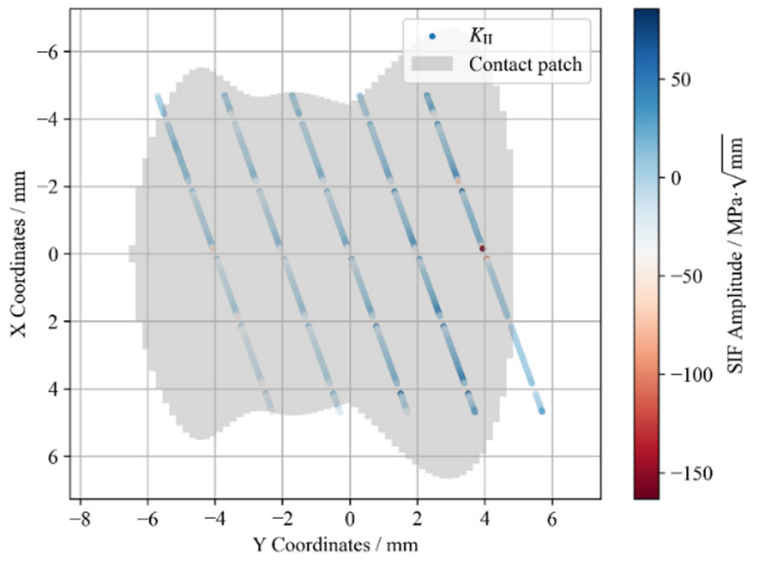

(d)

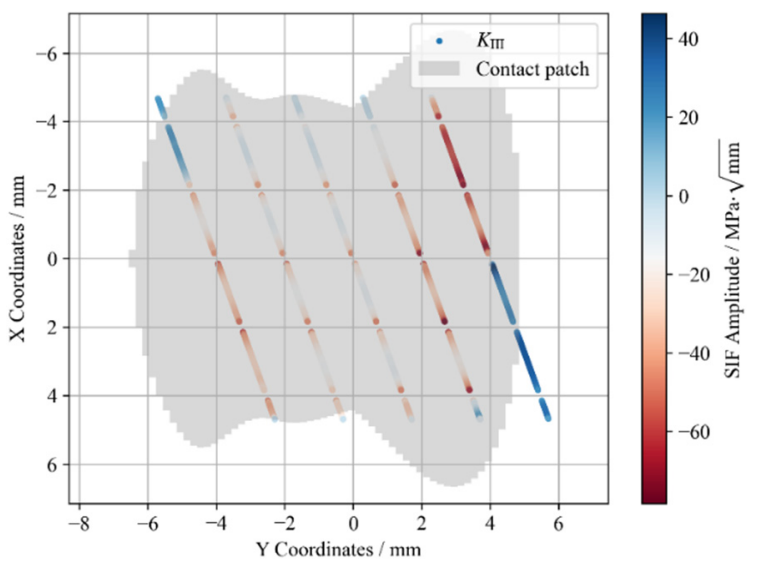

(f)

Figure 12. Results of SIFs at the transition curve: (a) SIF of type I cracks without the grinding marks; (b) SIF of type I cracks with the grinding marks; (c) SIF of type II cracks without the grinding marks; (d) SIF of type II cracks with the grinding marks; (e) SIF of type III cracks without the grinding marks; (f) SIF of type III cracks with the grinding marks.

\subsubsection{Circular Curve}

It can be seen from Figure 13a,b that the value of the SIF in the circular curve is much higher than that in a straight line or a transition curve. In terms of distribution state, it is also clear that the adjacent contact patch is prone to crack propagation. For the model without grinding marks, the maximum value of the SIF of type I is $15.05 \mathrm{MPa} / \mathrm{mm}^{0.5}$. For the model with grinding marks, the SIF is high in the intersection area of grinding marks and the cracks. The maximum value of type I SIF reaches $56.43 \mathrm{MPa} / \mathrm{mm}^{0.5}$, indicating that poor grinding works easily lead to the rapid progress of type I cracks. For type II crack propagation in the circular curve section, it can be seen from Figure $13 \mathrm{c}$, d that the $K_{\mathrm{II}}$ value is mainly distributed on the contact surfaces of the wheel and rail. For the condition without grinding marks, the maximum value is $11.73 \mathrm{MPa} / \mathrm{mm}^{0.5}$. For the state with grinding marks, a higher value appears in the intersectional area of grinding marks and cracks. The overall maximum value is $65.36 \mathrm{MPa} / \mathrm{mm}^{0.5}$, and its $K_{\text {II }}$ value is significantly higher than that of the state without grinding marks, indicating that the state of grinding marks can easily lead to the rapid development of type II cracks. As for the results of the SIF values of type III cracks, as shown in Figure 13e,f, the grinding marks significantly enlarge the values of SIF near the intersection point of grinding marks and cracks. 


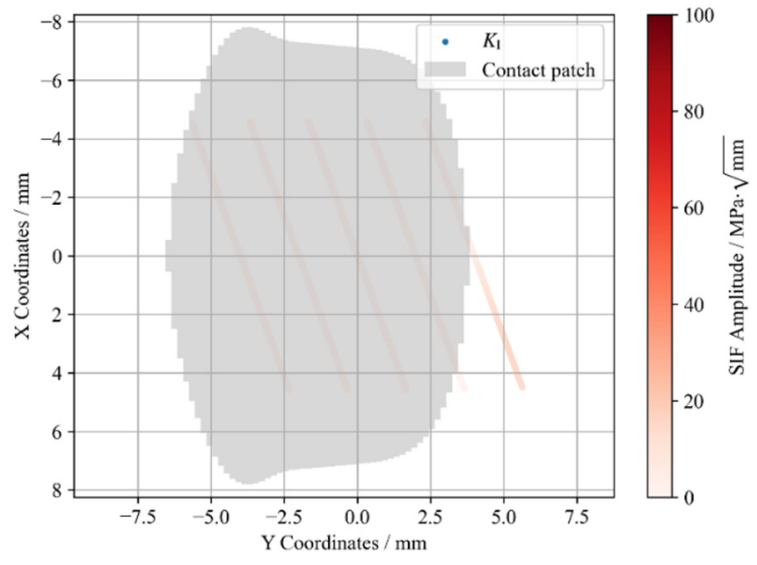

(a)

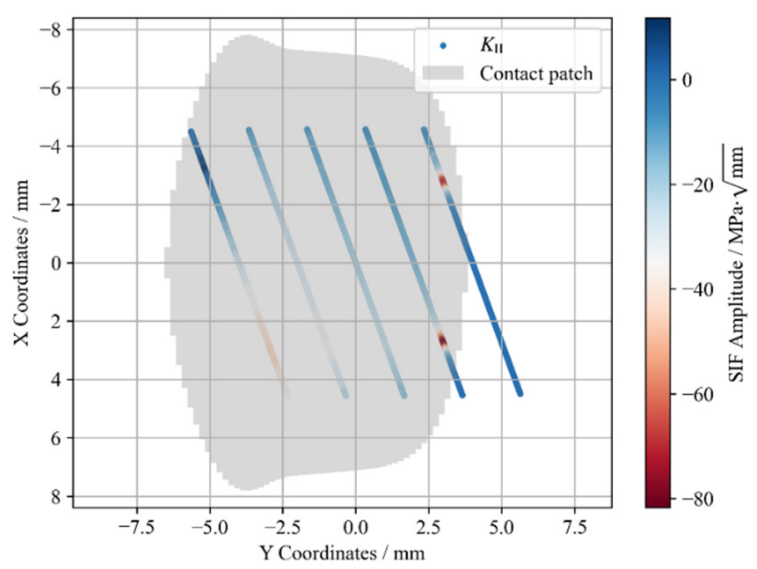

(c)

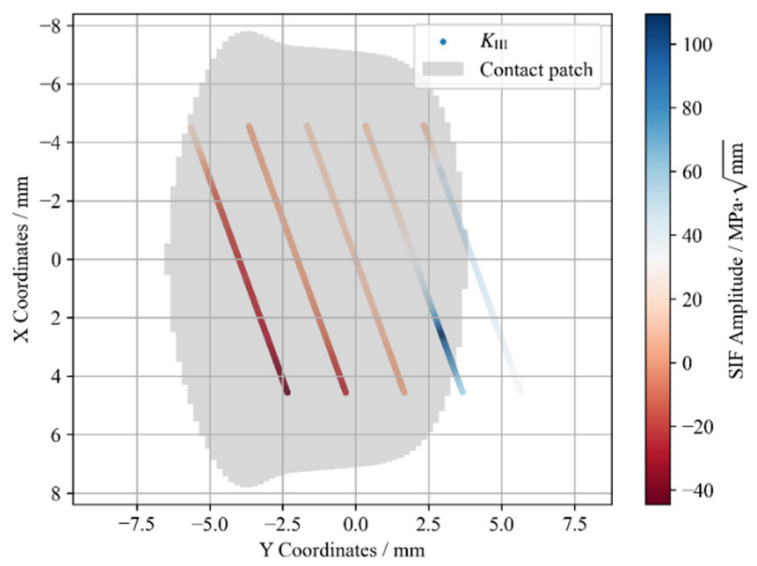

(e)

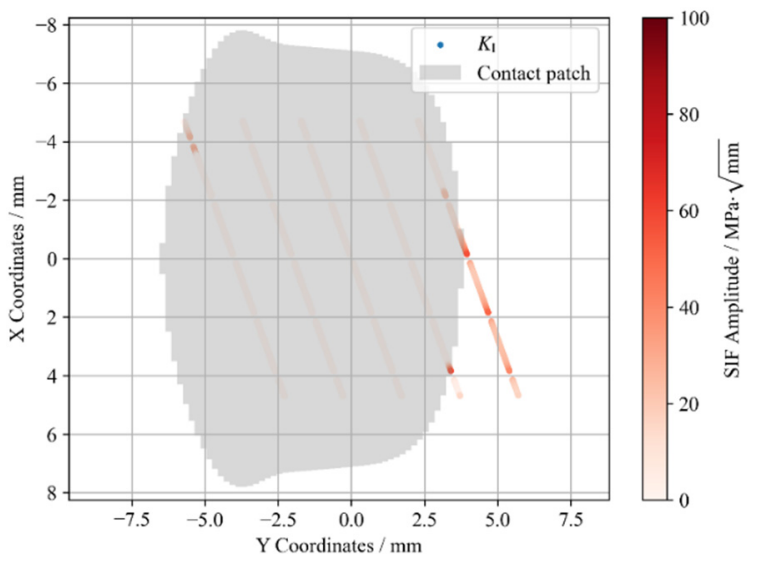

(b)

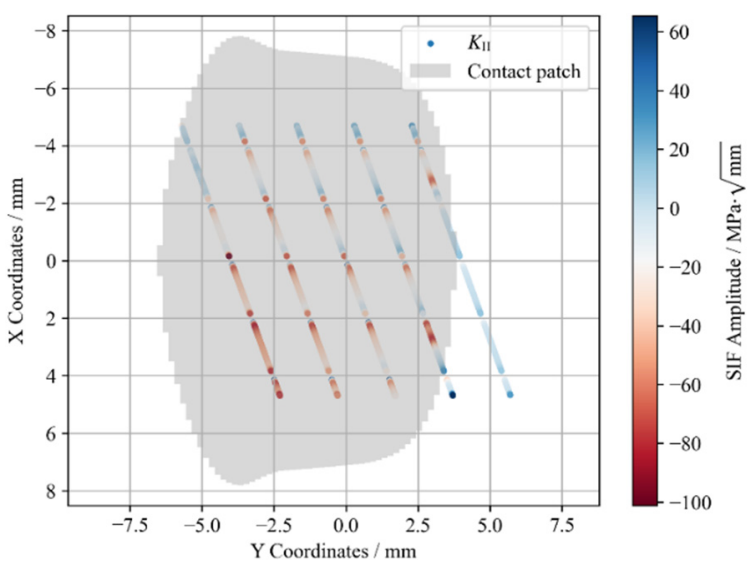

(d)

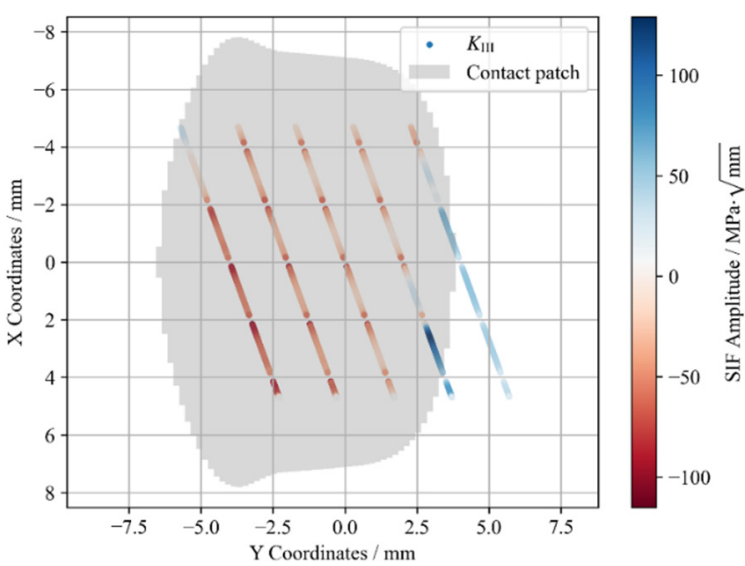

(f)

Figure 13. Results of SIFs at the circular curve: (a) SIF of type I cracks without the grinding marks; (b) SIF of type I cracks with the grinding marks; (c) SIF of type II cracks without the grinding marks; (d) SIF of type II cracks with the grinding marks; (e) SIF of type III cracks without the grinding marks; (f) SIF of type III cracks with the grinding marks.

From Figure 14, the results of SIFs with grinding marks are higher than in the condition without grinding marks in all three cases. This indicates that grinding marks increase trends in crack propagation in rail surfaces, and it provides a theoretical answer to the question put forward in Section 3. 


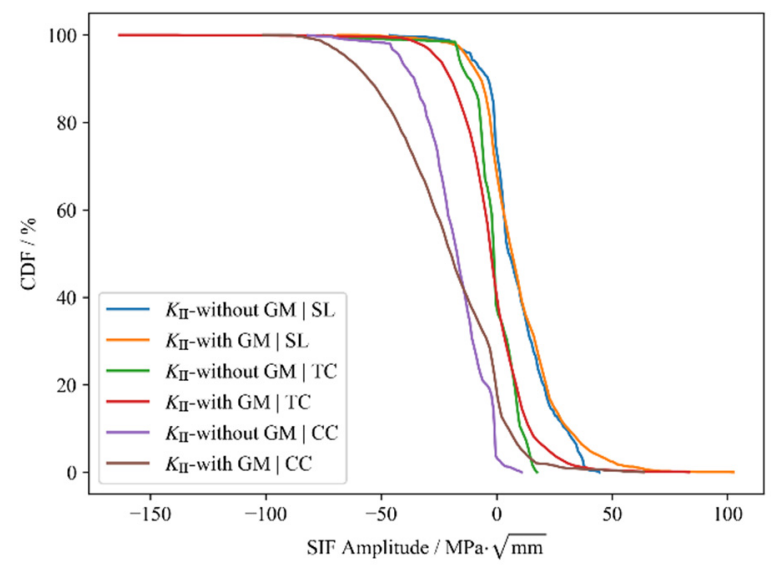

(a)

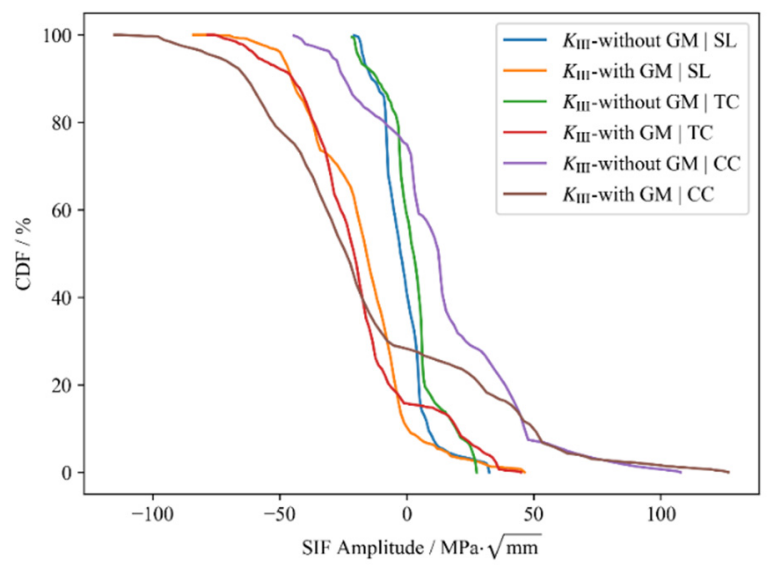

(b)

Figure 14. CDF contrast in SIFs under different conditions: (a) contrast in type II SIFs; (b) contrast in type III SIFs; GM-grinding marks; SL—straight line; TC—-transition curve; CC—circular curve.

By comparing the results above, it can be seen that the SIF values at the crack tip of the circular curve are higher than they are at the straight line and the transition curve, indicating that it is relatively easy for a crack to expand in the circular curve. This is consistent with experience gathered from the field. The residual surface grinding marks from a poor grinding process accelerate the evolution of cracks on a railhead, thus reducing its plasticity resistance. As such, the deterioration process of plastic flow corrugation enters a rapid progression that advances quickly.

Therefore, the intersection of grinding marks and fatigue cracks after grinding should be avoided by improving the material, removing the volume of the grinding works to absolutely remove RCF defects, or optimizing grinding quality to reduce grinding marks.

\section{Conclusions}

The corrugation growth properties including wavelength, depth, and evolution process are investigated and a rapid deterioration phenomenon affected by grinding works was found by the 69-days long continuous test on the sharp curve of the heavy haul railway. To analyze the reason for the rapid deterioration of corrugation and the influence of the grinding marks, numerical methodologies based on the FEM and the fracture mechanics were conducted. The main conclusions are as follows:

1. The measured data show that the on-site rail corrugation has a significant plastic flow pattern and RCF cracks on the railhead. At the end of the field test, the maximum amplitude reached $350 \mu \mathrm{m}$, with the main wavelength around $160 \mathrm{~mm}$.

2. After grinding, the trend in corrugation amplitude growth is moderate for a period of time. The residual surface grinding marks caused by a poor grinding process accelerate the evolution of corrugation so that the deterioration process can progress rapidly. During this process, the average peak-to-peak values can increase up to $1.4 \mu \mathrm{m} /$ day.

3. In the circular curve section, rail surface cracks tended to expand more easily compared to those in the straight line and transition sections. A higher SIFs value appear in the intersectional area between grinding marks and cracks. Grinding marks from poor grinding works will increase the SIFs of cracks, promote the rapid expansion of surface cracks, reduce the plastic resistance of contact area of rails indirectly, and result in the rapid development of plastic flow corrugation.

Our study on the impact of poor grinding quality on corrugation indicates that fatigue cracks on a railhead should be eliminated thoroughly in the process of rail grinding. As the 
bad influence of poor grinding quality on rail corrugation shows, the intersections between grinding marks and fatigue cracks should be avoided to prevent rapid deterioration.

Author Contributions: Funding acquisition, H.X.; Conceptualization, F.J. and H.X.; methodology, F.J.; validation, F.J., H.Y. and W.L.; formal analysis, F.J.; writing-original draft preparation, F.J.; writing—review and editing, F.J., M.M.N. and H.X.; visualization, F.J.; supervision, H.X.; All authors have read and agreed to the published version of the manuscript.

Funding: This research was funded by the Fundamental Research Funds for the Central Universities (Grant No. 2020YJS127), National Natural Science Foundation of China (Grant No.51978045), and Scientific and Technological Innovation Project of China Shenhua Energy Company Limited (Grant No. SHGF-16-50).

Conflicts of Interest: The authors declare no conflict of interest.

\section{References}

1. Oostermeijer, K.H. Review on Short Pitch Rail Corrugation Studies. Wear 2008, 265, 1231-1237. [CrossRef]

2. Jiang, Z.; Si, D.; Li, W.; Du, X. On Rail Corrugation of High Speed Railway. China Railw. Sci. 2014, 35, 9-14.

3. Li, W.; Du, X.; Wang, H.; Wu, L.; Li, X.; Wen, Z.; Jin, X. Investigation into the Mechanism of Type of Rail Corrugation of Metro. Jixie Gongcheng Xuebao J. Mech. Eng. 2013, 49, 26-32. [CrossRef]

4. Jin, X.; Wen, Z.; Wang, K. Theoretical Medel and Numerical Method of Rail Corrugation. J. Traffic Transp. Eng. 2005, 5, 12-18.

5. Wang, K.; Liu, P.; Zhai, W.; Huang, C.; Chen, Z.; Gao, J. Wheel/rail dynamic interaction due to excitation of rail corrugation in high-speed railway. Sci. China Technol. Sci. 2015, 58, 226-235. [CrossRef]

6. Xiao, H.; Yang, S.; Wang, H.; Wu, S.X. Initiation and Development of Rail Corrugation Based on Track Vibration in Metro Systems. Proc. Inst. Mech. Eng. Part F J. Rail Rapid Transit 2018, 232, 2228-2243. [CrossRef]

7. Ekberg, A.; Kabo, E.; Nielsen, J.C.O.; Lundén, R. Subsurface Initiated Rolling Contact Fatigue of Railway Wheels as Generated by Rail Corrugation. Int. J. Solids Struct. 2007, 44, 7975-7987. [CrossRef]

8. Grassie, S.L.; Kalousek, J. Rail Corrugation: Characteristics, Causes and Treatments. Proc. Inst. Mech. Eng. Part F J. Rail. Rapid Transit 1993, 207, 57-68. [CrossRef]

9. Grassie, S.L. Rail Irregularities, Corrugation and Acoustic Roughness: Characteristics, Significance and Effects of Reprofiling. Proc. Inst. Mech. Eng. Part F J. Rail Rapid Transit 2012, 226, 542-557. [CrossRef]

10. Meehan, P.A.; Batten, R.D.; Bellette, P.A. The Effect of Non-Uniform Train Speed Distribution on Rail Corrugation Growth in Curves/Corners. Wear 2016, 366-367, 27-37. [CrossRef]

11. Meehan, P.A.; Bellette, P.A.; Batten, R.D.; Daniel, W.J.T.; Horwood, R.J. A Case Study of Wear-Type Rail Corrugation Prediction and Control Using Speed Variation. J. Sound Vib. 2009, 325, 85-105. [CrossRef]

12. Jin, X.S.; Wen, Z.F. Effect of Discrete Track Support by Sleepers on Rail Corrugation at a Curved Track. J. Sound Vib. 2008, 315, 279-300. [CrossRef]

13. Jin, X.; Wen, Z.; Wang, K.; Xiao, X. Effect of Passenger Car Curving on Rail Corrugation at a Curved Track. Wear 2006, 260, 619-633. [CrossRef]

14. Matsumoto, A.; Sato, Y.; Ono, H.; Tanimoto, M.; Oka, Y.; Miyauchi, E. Formation Mechanism and Countermeasures of Rail Corrugation on Curved Track. Wear 2002, 253, 178-184. [CrossRef]

15. Torstensson, P.T.; Schilke, M. Rail Corrugation Growth on Small Radius Curves-Measurements and Validation of a Numerical Prediction Model. Wear 2013, 303, 381-396. [CrossRef]

16. Teng, Y.; Liu, H.; Liu, J.; Wang, C.; Ma, Z. A Rail Corrugation Measurement Method Based on Data Splicing. Measurement 2020, 156, 107560. [CrossRef]

17. Egana, J.I.; Vinolas, J.; Gil-Negrete, N. Effect of Liquid High Positive Friction (HPF) Modifier on Wheel-Rail Contact and Rail Corrugation. Tribol. Int. 2005, 38, 769-774. [CrossRef]

18. Daniel, W.J.T.; Cheng, C.Y.; Meehan, P.A. Modelling the Effects of Friction Modifiers on Rail Corrugation in Cornering. Veh. Syst. Dyn. 2008, 46, 845-866. [CrossRef]

19. Zhang, H.; Liu, W.; Liu, W.; Wu, Z. Study on the Cause and Treatment of Rail Corrugation for Beijing Metro. Wear 2014, 317, 120-128. [CrossRef]

20. Liu, W.; Zhang, H.; Liu, W.; Thompson, D.J. Experimental Study of the Treatment Measures for Rail Corrugation on Tracks with Egg Fasteners in the Beijing Metro. Proc. Inst. Mech. Eng. Part F J. Rail Rapid Transit 2018, 232, 1360-1374. [CrossRef]

21. Xin, T.; Wang, S.; Gao, L.; Huo, H.; Ding, Y.; Wang, P.; Chen, P.; Liu, P. Field Measurement of Rail Corrugation Influence on Environmental Noise and Vibration: A Case Study in China. Measurement 2020, 164, 108084. [CrossRef]

22. Satoh, Y.; Iwafuchi, K. Effect of Rail Grinding on Rolling Contact Fatigue in Railway Rail Used in Conventional Line in Japan. Wear 2008, 265, 1342-1348. [CrossRef]

23. Ishida, M.; Abe, N.; Moto, T. The Effect of Preventive Grinding on Rail Surface Shellings. Railw. Tech. Res. Inst. Q. Rep. 1998, 39, 136-141. 
24. Asplund, M.; Famurewa, S.M.; Schoech, W. A Nordic Heavy Haul Experience and Best Practices. Proc. Inst. Mech. Eng. Part F J. Rail Rapid Transit 2017, 231, 794-804. [CrossRef]

25. EN 15610:2009. Railway Applications-Noise Emission-Rail Roughness Measurement Related to Rolling Noise Generation; BSI-British Standards Institution: London, UK, 2009.

26. EN 13231-3. 2012 Railway Application-Track Acceptance of Works_Part 3: Acceptance of Rail Grinding, Milling and Planning Work in Track; BSI-British Standards Institution: London, UK, 2012.

27. Management Measures for Grinding of High Speed Railway; China State Railway Group Co., Ltd.: Beijing, China, 2014.

28. EN ISO 3095:2013. Acoustics-Railway Applcations-Measurement of Noise Emitted by Railbound Vehicles; BSI-British Standards Institution: London, UK, 2013.

29. GB/T 3449-2011. Acoustics-Mearsurement of Noise inside Railbound Vehicles; Standards Press of China: Beijing, China, 2011.

30. Bower, A.F. Cyclic Hardening Properties of Hard-Drawn Copper and Rail Steel. J. Mech. Phys. Solids 1989, 37, 455-470. [CrossRef]

31. Ayasse, J.B.; Chollet, H. Determination of the Wheel Rail Contact Patch in Semi-Hertzian Conditions. Veh. Syst. Dyn. 2005, 43, 161-172. [CrossRef]

32. Quost, X.; Sebes, M.; Eddhahak, A.; Ayasse, J.B.; Chollet, H.; Gautier, P.E.; Thouverez, F. Assessment of a Semi-Hertzian Method for Determination of Wheel-Rail Contact Patch. Veh. Syst. Dyn. 2006, 44, 789-814. [CrossRef] 